\title{
Impact of Newer Medications for Type 2 Diabetes on Body Weight
}

\author{
Sue D. Pedersen
}

Published online: 8 January 2013

(C) Springer Science+Business Media New York 2013

\begin{abstract}
Most patients with type 2 diabetes (T2DM) struggle with excess body weight. Many management strategies for achievement of euglycemia in T2DM are associated with weight gain, which worsens insulin resistance over time, increases health risk associated with obesity, and is associated with poor compliance with treatment. This review will discuss a host of new medications for management of hyperglycemia that have emerged and are emerging which are weight neutral, or facilitate weight loss. Incretin therapies are reviewed, including DPP-4 inhibitors which are weight neutral, and GLP-1 receptor agonists which can facilitate weight loss. SGLT-2 inhibitors, anticipated to become available soon, facilitate modest weight loss. Pramlintide can improve glycemic control and facilitate weight loss in T2DM patients on concomitant insulin therapy. The bile acid sequestering agent colesevelam, more recently approved for management of T2DM, modestly improves glycemic control and is weight neutral. The advent of these newer therapies makes it increasingly possible to optimize concomitant management of type 2 diabetes and obesity.
\end{abstract}

Keywords Type 2 diabetes mellitus - Obesity - Weight loss · Incretins · GLP-1 · Sodium glucose transporter 2 - Amylin .

Liraglutide $\cdot$ Exenatide $\cdot$ Sitagliptin $\cdot$ Saxagliptin .

Linagliptin · Vildagliptin · Dapagliflozin · Canagliflozin .

Pramlintide $\cdot$ Colesevelam $\cdot$ Newermedications $\cdot$ Body weight

\section{Introduction}

There is a rising global prevalence of type 2 diabetes (T2DM), such that it has become one of today's most challenging health

S. D. Pedersen $(\triangle)$

C-ENDO Endocrinology Centre, Suite 240, 1016 68th Ave SW,

Calgary, AB T2V 4J2, Canada

e-mail: drsuepedersen@gmail.com

URL: www.drsue.ca issues. In the United States, it is estimated that $8.3 \%$ of the population has T2DM, with an additional $35 \%$ of American adults having prediabetes [1].

The rise in T2DM parallels the increasing prevalence of obesity, with $35.7 \%$ of American adults being obese, and another $1 / 3$ of adults being overweight [2]. Ninety percent of patients with T2DM are overweight or obese, and over $60 \%$ of cases of type 2 diabetes can be attributed directly to excess body weight [3]. Outcomes are significantly worse in type 2 diabetic patients who are also obese, including an increased risk of cardiovascular disease and all-cause mortality of $44 \%$ and $71 \%$, respectively [4].

Many management strategies that have traditionally been available for the management of hyperglycemia in T2DM have been accompanied by weight gain as an unwanted side effect [5••]. This creates a paradox in management, in that with weight gain, insulin resistance worsens, and while diabetes control may initially improve, the underlying insulin resistance progresses, potentially paving the way for an increased need for diabetes medications in the future [6]. Each $1 \mathrm{lb}$ increase in body weight has been associated with a $2 \%$ increased odds of progression of diabetes [7]. Patients' desire to avoid weight gain may also compromise compliance with treatment [8].

In the last several years, a host of new diabetes medications have emerged and are being developed to address this gap in diabetes care, designed to help to control hyperglycemia without causing weight gain. This review summarizes currently available and anticipated to soon become available treatment strategies for management of hyperglycemia in T2DM that do not result in weight gain (Table 1).

\section{Traditional Antihyperglycemic Agents: Effect on Body Weight}

Several traditionally available agents for the management of T2DM result in weight gain as an unwanted side effect. A 
Table 1 Newer agents for glycemic control in type 2 diabetes mellitus that do not cause weight gain

\begin{tabular}{|c|c|c|c|c|}
\hline $\begin{array}{l}\text { Medication } \\
\text { class }\end{array}$ & Mechanism & $\begin{array}{l}\mathrm{A} 1 \mathrm{C} \\
\text { reduction }\end{array}$ & $\begin{array}{l}\text { Typical effect } \\
\text { on weight }\end{array}$ & $\begin{array}{l}\text { Mode of } \\
\text { administration }\end{array}$ \\
\hline $\begin{array}{l}\text { DPP } 4 \\
\text { Inhibitors }\end{array}$ & $\begin{array}{l}\text { prolongation of endogenous GLP-1 activity, leading to } \\
\text { increased postprandial insulin release, glucagon suppression }\end{array}$ & $\begin{array}{l}-0.5 \text { to } \\
-0.9 \%\end{array}$ & neutral & oral \\
\hline $\begin{array}{l}\text { GLP-1 } \\
\text { Receptor } \\
\text { Agonists }\end{array}$ & $\begin{array}{l}\text { pharmacologic levels of GLP-1 activity, leading to increased postprandial } \\
\text { insulin release, glucagon suppression, slowing of gastric } \\
\text { emptying, central satiety stimulation }\end{array}$ & $\begin{array}{c}-0.8 \% \text { to } \\
-1.5 \%\end{array}$ & $\begin{array}{l}-3 \mathrm{~kg} \text { to }-5 \mathrm{~kg} \\
\text { weight loss }\end{array}$ & subcutaneous \\
\hline $\begin{array}{l}\text { SGLT-2 } \\
\text { Inhibitors* }\end{array}$ & block renal glucose reabsorption & $\begin{array}{l}-0.5 \text { to } \\
-0.8 \%\end{array}$ & $\begin{array}{l}-2 \mathrm{~kg} \text { to }-3 \mathrm{~kg} \\
\text { weight loss }\end{array}$ & oral \\
\hline Pramlintide & $\begin{array}{l}\text { pharmacologic levels of amylin activity, leading to suppression of glucagon, } \\
\text { slowing of gastric emptying, central satiety stimulation }\end{array}$ & $\begin{array}{c}-0.5 \% \text { to } \\
-1.0 \%\end{array}$ & $\begin{array}{l}-1.5 \mathrm{~kg} \text { weight } \\
\text { loss }\end{array}$ & subcutaneous \\
\hline Colesevelam & unclear; increased glycolytic disposal of oral glucose & $\begin{array}{l}-0.3 \text { to } \\
-0.5 \%\end{array}$ & neutral & oral \\
\hline
\end{tabular}

*Not yet in clinical use

recent meta-analysis examining the effect of noninsulin antidiabetic drugs added to metformin therapy in T2DM found the weight gain associated with use of sulfonylurea, glinide, and thiazolidinediones to be increased compared to placebo, at $2.06 \mathrm{~kg}, 1.77 \mathrm{~kg}$, and $2.08 \mathrm{~kg}$, respectively [9]. Insulin therapy is long known to be associated with weight gain [10]. Alpha glucosidase inhibitors have been found to be weight neutral [9] to $-1.0 \mathrm{~kg}$ weight negative [11] in meta-analyses. Metformin, the recommended first line therapy for T2DM [12-14] is slightly weight negative, with trials reporting a weight loss ranging from $-0.6 \mathrm{~kg}$ to $-2.9 \mathrm{~kg}[15-17]$.

Insulin, sulfonylureas, and glinides are additionally associated with an increased risk of hypoglycemia [11], episodes of which require immediate correction with oral carbohydrate. These unwanted calories may represent one mechanism by which these agents cause weight gain.

\section{Incretin Therapies}

There are two main incretin hormones known in human physiology, namely, glucagon like peptide - 1 (GLP-1) and glucose-dependent insulinotropic polypeptide (GIP), with GLP-1 having the predominant effects.

GLP-1 is a peptide that is released from the L cells of the small intestine in response to the entry of nutrients into the intestine [18] via neuroendocrine mediators (acetylcholine, gastrin-releasing peptide, and GIP), and also in response to direct intraluminal contact between ingested nutrients and GLP-1 secreting cells [19]. GLP-1-stimulates insulin release from the beta cells of the pancreas in response to a meal, and is thought to account for $50-70 \%$ of postprandial insulin secretion. In addition, GLP-1 suppresses glucagon release from alpha cells of the pancreas [20]. The insulinotropic and glucagon suppressive effects of GLP-1 are only active in the presence of hyperglycemia; the clinical implication of this is that incretin therapies do not cause hypoglycemia.
Further, GLP-1 slows gastric emptying [21], and also promotes satiety by stimulating the central satiety center in the paraventricular nucleus of the hypothalamus [22]. It is by these latter two mechanisms that incretin therapies do not induce weight gain, and in the case of GLP-1 receptor agonists, can induce weight loss.

In patients with type 2 diabetes, it has been demonstrated that GLP-1 levels are significantly reduced compared to healthy controls [23]. There is additionally an element of impairment of the beta cell insulin secretory response to GLP-1 in type 2 diabetics [24]. Incretin therapies have been developed as a treatment for type 2 diabetes, in an attempt to counteract these pathophysiologic disturbances in GLP-1 physiology. The incretin therapies can be categorized into two subgroups, namely, DPP-4 inhibitors, and GLP-1 receptor agonists.

\section{DPP-4 Inhibitors}

The dipeptidyl peptidase type 4 (DPP-4) inhibitors are molecules that work by delaying the degradation of endogenous GLP-1. Shortly after its secretion, endogenous GLP-1 is rapidly degraded by the DPP-4 enzyme [25], such that the half life of endogenous GLP-1 is approximately 11.5 minutes [26]. By slowing degradation of endogenous GLP-1, the DPP-4 inhibitors provide prolongation of physiologic levels of GLP-1.

There are currently four DPP-4 inhibitors that are being utilized in clinical practice (though approval of specific medications varies by country): sitagliptin, saxagliptin, linagliptin, and vildagliptin. They are taken orally once daily, with the exception of vildagliptin, which is taken once daily with sulfonylurea, but twice daily together with metformin [27].

The DPP-4 inhibitors are viewed as weight neutral medications [28••], as found in an extensive meta-analysis [9]. The A1C reduction seen with DPP-4 inhibitors is equivalent 
to that seen with other oral agents, ranging from $-0.6 \%$ to $-1.1 \%$ [29]. Overall, there appears to be no difference in terms of $\mathrm{A} 1 \mathrm{C}$ reduction nor change in body weight amongst the DPP-4 inhibitors. In a head-to-head trial of saxagliptin $5 \mathrm{mg}$ daily vs sitagliptin $100 \mathrm{mg}$ daily, body weight reduction was small but equivalent in both groups $(-0.4 \mathrm{~kg})$ after 18 weeks of treatment [30]. Studies of linagliptin and vildagliptin have also evidenced weight neutrality [31-33].

\section{GLP-1 Receptor Agonists}

GLP-1 receptor agonists (GLP-1 RAs) take advantage of the incretin system by providing exogenous GLP-1 by way of subcutaneous injection. As they provide supraphysiologic GLP-1 activity, they are more potent than DPP-4 inhibitors, both in terms of A1C reduction (though this varies by agent) and in terms of weight loss. In the early phases of treatment, nausea may be experienced due to the effect of slow gastric emptying; the proportion of patients who experience this side effect varies by agent, but does tend to improve with time for most patients. The weight loss seen with GLP-1 RAs is independent of the nausea effect in most cases, and the weight loss is sustained despite resolution of nausea symptoms.

Exenatide was the first of the GLP-1 RAs to come into clinical use, receiving approval from the FDA in 2005. Exenatide is synthetic exendin-4, a naturally occurring component of the saliva of the Gila monster, sharing $53 \%$ homology with human GLP-1. It is resistant to endogenous degradation by DPP-IV, and therefore has a prolonged half life of 2.4 hours [34].

In addition to achieving an average $1.0 \% \mathrm{~A} 1 \mathrm{C}$ reduction in patients with T2DM [35], a sustained weight lowering effect has been shown. A 30 week study of exenatide vs placebo found a dose dependent decrease in A1C $(-0.4 \%$ and $-0.8 \%$ for $5 \mathrm{mcg}$ and $10 \mathrm{mcg}$ twice daily, respectively, vs $+0.08 \%$ on placebo) and weight $(-1.6 \mathrm{~kg}$ and $-2.8 \mathrm{~kg}$ respectively, vs $-0.3 \mathrm{~kg}$ on placebo) [36]. In a two year long term extension of this study, all patients were placed on exenatide treatment, and a weight loss averaging about $-5.4 \mathrm{~kg}$ at two years was observed, and was found to be unlikely to be driven by nausea [37]. The weight loss seen with exenatide was dependent on the starting BMI, with greater weight loss seen with a higher starting BMI.

Exenatide therapy is administered subcutaneously at an initial dose of $5 \mathrm{mcg}$ twice daily, given within 60 minutes before the morning and evening meal. The dose can be increased to $10 \mathrm{mcg}$ twice daily if well tolerated after four weeks, if additional glycemic control is needed.

Liraglutide is a GLP-1 analog, sharing $97 \%$ homology with human GLP-1, that has been modified to non-covalently bind to serum albumin via a lipid side chain, resulting in slower degradation by DPP-IV. Liraglutide has a half life of
13 hours, and is therefore dosed once daily without regard to meals. A rodent study suggests that the effect of liraglutide to slow gastric emptying is not sustained over time, and that regulation of appetite signals in the brain is the main mechanism for liraglutide induced weight loss [38]. In contrast, this study showed that gastric emptying is slowed for a longer period of time with exenatide, suggesting that this mechanism may be more important for exenatide's effect to reduce weight.

Weight data from seven phase 3 randomized trials in the liraglutide development program for T2DM were recently evaluated in a meta-analysis [39]. The estimated weight loss seen with liraglutide $1.2 \mathrm{mg}$ and $1.8 \mathrm{mg}$ vs placebo over 26 weeks was $-0.78 \mathrm{~kg}$ and $-1.2 \mathrm{~kg}$, respectively. However, the estimated weight loss seen with liraglutide $1.2 \mathrm{mg}$ and $1.8 \mathrm{mg}$ vs active comparator was $-2.7 \mathrm{~kg}$ and $-3.2 \mathrm{~kg}$, respectively. A higher initial BMI was associated with slightly greater weight loss, and mean weight loss was slightly larger the longer gastrointestinal side effects persisted. While patients experiencing a higher degree of weight loss generally had greater $\mathrm{A} 1 \mathrm{C}$ reduction, $\mathrm{A} 1 \mathrm{C}$ change did not demonstrate a clear correlation with the amount of weight lost.

In a six month randomized controlled trial comparing liraglutide $1.8 \mathrm{mg}$ daily vs exenatide $10 \mathrm{ug}$ twice daily, liraglutide was found to be superior in terms of A1C reduction $(-1.1 \%$ and $-0.8 \%$, respectively), but there was no significant difference in terms of weight loss, with weight loss of $-3.2 \mathrm{~kg}$ and $-2.9 \mathrm{~kg}$, respectively [40]. While the proportion of patients affected by nausea was initially similar between the two groups at approximately $15 \%$, the nausea resolved more quickly in the liraglutide group. At 26 weeks, $2.5 \%$ of the liraglutide group had persistent nausea, compared with $8.6 \%$ of the exenatide group.

Liraglutide therapy is commenced at a dose of $0.6 \mathrm{mg}$ subcutaneously once daily; if well tolerated after one week, the dose is increased to $1.2 \mathrm{mg}$. After another week, the dose can be further increased to $1.8 \mathrm{mg}$ daily; both $1.2 \mathrm{mg}$ and $1.8 \mathrm{mg}$ daily are considered therapeutic doses.

Exenatide q weekly (QW) is a once weekly preparation of exenatide, which utilizes biodegradable polymeric microspheres to provide an extended release at a controlled rate; steady state serum exenatide concentrations are achieved after 6-7 weeks of treatment [41]. In a 30 week study comparing exenatide weekly with twice daily exenatide, A1C reduction was superior on exenatide QW $(-1.9 \%$ vs $-1.5 \%$ for exenatide bid). Weight loss was not significantly different ( $-3.7 \mathrm{~kg}$ vs $-3.6 \mathrm{~kg}$, respectively), despite significantly less nausea being reported in the QW group (26\% vs $35 \%$ respectively) [42]. Weight loss was observed in patients who reported no nausea throughout the trial $(70 \%)$ in both groups, though the weight loss seen was modestly greater in patients who reported at least one episode of nausea. 
In an open label study of exenatide $2 \mathrm{mg}$ QW versus liraglutide $1.8 \mathrm{mg}$, exenatide $\mathrm{QW}$ failed to meet noninferiority criteria for $\mathrm{A} 1 \mathrm{C}$ reduction $(-1.28$ vs $-1.48 \%$, respectively), and patients on exenatide had significantly less weight loss than those on liraglutide ( $-2.68 \mathrm{~kg}$ vs $-3.58 \mathrm{~kg}$, respectively) [43]. However, more patients in the liraglutide group discontinued the medication due to GI side effects (5.3\%) compared to exenatide QW (2.6\%).

Other GLP-1 RAs currently under development for the treatment of T2DM include once daily lixisenatide [44], and once weekly albiglutide [45] and semaglutide [46]. Patients utilizing GLP-1 RAs as part of their T2DM therapy have reported improved quality of life and satisfaction with treatment, particularly for the once daily and once weekly preparations [45, 47-49].

\section{Combination Therapy with GLP-1 Receptor Agonists and Insulin}

GLP-1 RAs can also improve glycemic control and facilitate weight loss (or minimize weight gain) in patients with T2DM on insulin therapy, a group in whom it is often quite difficult to effect weight loss due to the adipogenic qualities of insulin as well as the degree of insulin resistance manifested by these patients. A study compared the effect of adding exenatide twice daily vs placebo to patients on preexisting therapy with insulin glargine; insulin glargine was titrated to target glycemic control in both groups. After 30 weeks, a superior $\mathrm{A} 1 \mathrm{C}$ reduction was seen with exenatide $(-1.74 \%$ vs $-1.04 \%$ in the placebo group), with an average insulin glargine dose increase of 13 units in the exenatide group compared to 20 units in the placebo group. Patients in the exenatide group lost $-1.78 \mathrm{~kg}$ during the study, whereas patients in the placebo group gained $+0.96 \mathrm{~kg}$ [50].

Liraglutide has also been studied in combination with insulin. A six month study was conducted, in which insulin detemir was added in a randomized fashion to T2DM patients who had not achieved A1C target of $<7 \%$ on metformin and 3 months of liraglutide (run-in phase), versus continuation without insulin detemir. After 26 weeks, weight decreased by $-0.16 \mathrm{~kg}$ in the insulin group (in addition to $-3.5 \mathrm{~kg}$ lost during the liraglutide run-in), vs $0.95 \mathrm{~kg}$ of weight loss without insulin detemir; A1C and body weight changes were sustained at 1 year [51, 52]. Thus, whereas insulin attenuated the liraglutide-induced weight loss to some extent, weight gain was not seen with addition of insulin therapy.

It is important to recognize that the efficacy of GLP-1 RAs to improve glycemic control in patients with T2DM on insulin is likely to depend in part on the amount of residual beta cell function. As one of the mechanisms by which GLP-1 RAs improve glycemic control is by stimulating meal-induced insulin release, it follows that patients who require multiple dose intensive insulin therapy with basal and mealtime insulin are unlikely to have much endogenous beta cell function, and thus, this mechanism of GLP-1 RAs will not have a significant effect. However, the glucagon suppressive effect will still be relevant in these patients, and this, combined with the stimulation of satiety (inducing weight loss), can still have a significant impact to improve glycemic control, reduce insulin requirements, and facilitate weight loss in these patients.

\section{Future Considerations: GLP-1 Receptor Agonists as Obesity Therapy?}

Some GLP-1 RA analogs are currently under study as treatments for obesity in the absence of T2DM. In a randomized controlled, open label trial, different doses of liraglutide were compared to orlistat and placebo, in addition to a $-500 \mathrm{kcal}$ per day energy reduced diet and exercise counseling [53]. In the initial 20 weeks, a dose dependent response to liraglutide was seen, with $-7.2 \mathrm{~kg}$ of weight loss on the highest dose of liraglutide of $3.0 \mathrm{mg}$, compared with $-4.1 \mathrm{~kg}$ on orlistat and $-2.8 \mathrm{~kg}$ on placebo. During an extension of the study to 1 year, patients on liraglutide $3.0 \mathrm{mg}$ experienced an overall $-5.8 \mathrm{~kg}$ placebo-subtracted weight loss, and $-3.8 \mathrm{~kg}$ more than those on orlistat. This weight loss was predominantly body fat, with a $-15.4 \%$ decrease in body fat and a $-2.0 \%$ decrease in lean tissue being observed [54]. Mean change in waist circumference was also significantly greater with liraglutide $2.4 / 3.0 \mathrm{mg}$ compared to orlistat. Higher doses of liraglutide were associated with more nausea compared to lower doses, but most were transient and of mild or moderate intensity. The weight loss seen after 1 year on liraglutide $3.0 \mathrm{mg}$ was higher $(-10.0 \mathrm{~kg})$ for those with nausea and/or vomiting than those without $(-7.1 \mathrm{~kg})$, but weight loss without nausea/vomiting was still $-4.2 \mathrm{~kg}$ greater than placebo and $-2.3 \mathrm{~kg}$ greater than orlistat.

Following a 1 year extension of this study, all patients were then switched to $2.4 \mathrm{mg}$ liraglutide, then $3.0 \mathrm{mg}$ liraglutide (based on 20 week and 1 year results, respectively) [54]. At 2 years, patients on liraglutide 2.4/3.0 $\mathrm{mg}$ for the full duration of the study maintained a weight loss of $-7.8 \mathrm{~kg}$, and almost $70 \%$ of liraglutide 2.4/3.0 mg patients maintained weight loss of $>5 \%$ of screening weight at year 2 . In this study, prediabetes was reduced by $52 \%$, and improvement in other cardiovascular risk factors was also observed.

Exenatide has been studied in two smaller trials to date as an obesity therapy. One study showed $-5.1 \mathrm{~kg}$ of weight loss on exenatide vs $-1.6 \mathrm{~kg}$ on placebo after 26 weeks of treatment in addition to lifestyle intervention, with significantly greater normalization of prediabetes in the exenatide group (77\% and $56 \%$, respectively) [55]. Another study of 
41 obese women, conducted in a double blind, placebo controlled crossover fashion demonstrated that 16 weeks of exenatide $10 \mathrm{mcg}$ bid without any lifestyle intervention resulted in an average of $-2.5 \mathrm{~kg}$ weight loss compared with $-0.4 \mathrm{~kg}$ on placebo, as well as a significant decrease in waist circumference [56]. While nausea was seen more commonly on exenatide than on placebo, the severity of nausea decreased with time and did not correlate with weight loss.

No GLP-1 RA is currently approved for use as a weight loss agent.

\section{SGLT-2 Inhibitors}

Glucose reabsorption in the kidney is mediated by sodium glucose cotransporters (SGLT) located in the proximal tubules. There are two types of SGLT; SGLT2 is responsible for $98 \%$ of renal glucose reabsorption, whereas SGLT1 is responsible for only $2 \%$ [57]. An emerging class of oral medications, known as SGLT2 inhibitors, block SGLT2 mediated glucose reabsorption, resulting in iatrogenic glucosuria $[58,59 \bullet \bullet]$. It is by this mechanism that SGLT-2 inhibitors improve glycemic control and result in modest weight loss.

The SGLT-2 inhibitor dapagliflozin is anticipated to be in clinical use soon in Europe, as the Committee for Medicinal Products for Human Use recommended the granting of a marketing authorization in April 2012 [60]. In a trial of dapagliflozin vs placebo, dapagliflozin at a dose $10 \mathrm{mg}$ daily resulted in an $\mathrm{HbA1C}$ reduction of $-0.84 \%$ and a placebosubtracted weight loss of $-2.0 \mathrm{~kg}$ at six months [61]. In a one year trial comparing dapagliflozin to glipizide, a weight reduction of $-3.2 \mathrm{~kg}$ was seen in the dapagliflozin group, while the glipizide group gained $+1.2 \mathrm{~kg}$, with no significant difference in $\mathrm{A} 1 \mathrm{C}$ reduction ( $0.5 \%$ in both groups), and a significantly lower risk of hypoglycemia in the dapagliflozin group (3.5\% vs $40.8 \%$ in the glipizide group) [62].

Another study comparing dapagliflozin to placebo in patients with T2DM evaluated changes in body composition using dual energy x-ray absorptiometry (DXA) in each group. In addition to finding a placebo-subtracted weight loss of $-2.08 \mathrm{~kg}$ over six months with dapagliflozin therapy, they found that about $2 / 3$ of the weight loss observed with dapagliflozin was attributable to reductions in fat (with the other $1 / 3$ being a loss of lean body mass), compared to the weight loss in the placebo group being half fat, and half lean mass [63].

Dapagliflozin has been studied in combination with insulin, with evidence to suggest that dapagliflozin can facilitate weight loss and improve glycemic control in these patients. A 26 week study evaluated the effect of adding dapagliflozin to patients on pre existing insulin therapy, compared with placebo [64]. Patients on dapagliflozin
$10 \mathrm{mg}$ experienced an $\mathrm{A} 1 \mathrm{C}$ reduction $(-0.57 \%)$ compared with placebo group, despite a reduction in insulin requirement of -7 units compared to the placebo group. Body weight was reduced by $-2.0 \mathrm{~kg}$ compared with placebo. An extension to this study is currently underway.

The American Food and Drug Administration (FDA) has not yet approved dapagliflozin, due to concerns regarding an increased incidence of breast and bladder cancers, as well as hepatotoxicity [65].

Canagliflozin, another SGLT-2 inhibitor currently under study, has been shown to provide similar improvements in glycemic control and weight reduction [66].

\section{Pramlintide}

Pramlintide is an analog of the hormone amylin, a peptide that is stored in pancreatic beta cells and cosecreted with insulin. Amylin is deficient in patients with type 1 diabetes, and low in patients with T2DM who are later in the natural history of the disease where beta cell function is relatively low, as evidenced clinically by the need for exogenous insulin therapy [67]. Amylin affects glycemic control via several mechanisms, including suppression of postprandial glucagon and slowing the rate of gastric emptying. The anorectic effect of amylin and the gastric emptying effects appear to be mediated by stimulation of the area postrema of the hindbrain [68]. Contrary to the actions of GLP-1, amylin does not increase postprandial insulin release.

Amongst type 2 diabetics, pramlintide has been shown to improve glycemic control as well as facilitate weight loss, with the largest weight reductions being observed in more obese patients [69]. A 16 week study of pramlintide vs placebo added to therapy in T2DM patients treated with basal insulin with or without oral agents showed that pramlintide resulted in a greater A1C reduction $(-0.7 \%$ vs $-0.36 \%$ on placebo) and significant weight loss $(-1.6 \mathrm{~kg}$ vs $+0.7 \mathrm{~kg}$ on placebo) [70]. In a 6 month study where T2DM patients with inadequate control on basal insulin with or without oral agents were randomized to the addition of mealtime insulin vs pramlintide, patients on pramlintide maintained weight while patients on mealtime insulin gained an average of $+4.7 \mathrm{~kg}$, with similar improvements in glycemic control in each group $(-1.1 \%$ and $-1.3 \%$ in the pramlintide and mealtime insulin groups, respectively) [71].

In the US, pramlintide is indicated for use in type 1 diabetics, and in type 2 diabetics who require mealtime insulin [72]. In type 2 diabetics, the recommended initial dose is $60 \mathrm{mcg}$ administered subcutaneously with meals, titrated to $120 \mathrm{mcg}$ as tolerated with meals. Mealtime insulin doses must be reduced with the initiation of pramlintide therapy to avoid insulin-induced 
hypoglycemia. As pramlintide slows gastric emptying, nausea can occur with initiation of therapy, but this usually dissipates after 4 weeks of treatment. There are inadequate data to support the use of pramlintide with GLP-1 analog therapy in T2DM.

Pramlintide was under study with metreleptin as a combination therapy for the management of obesity, but this program was halted in 2011 [73].

\section{Colesevelam}

Colesevelam is a weight-neutral bile acid sequestering agent that lowers LDL cholesterol, which has also been shown to have a modest effect on glycemic control in T2DM, reducing $\mathrm{A} 1 \mathrm{C}$ by -0.3 to $-0.5 \%$ [74-76]. Available for several years for management of dyslipidemia, colesevelam was approved for treatment of T2DM by the FDA in 2008 [77]. The mechanism by which colesevelam improves glycemia is unclear, but appears to involve increased glycolytic disposal of oral glucose without a change in endogenous glucose production [78].

\section{Conclusions}

With the advent of several new therapies in our toolbox to manage glycemia in type 2 diabetes, it is becoming increasingly possible to manage type 2 diabetes with less iatrogenic weight gain, or while simultaneously facilitating weight loss. Not only does this result in a lesser degree of insulin resistance over time, it also results in a lower risk of obesity-mediated health complications over time, with early evidence to suggest improved quality of life and therefore the potential for improved patient compliance with treatment. As the availability and use of these agents are anticipated to broaden in parallel with increasing knowledge and experience with these medications, it is anticipated that the optimal concomitant management of T2DM and obesity will continue to improve as well.

Disclosure Conflicts of interest: S.D. Pedersen: is on the advisory board for Novo Nordisk, Merck, Sanofi Aventis, and Bristol Myers Squibb; has received honoraria for speaking/teaching for Eli Lilly, Novo Nordisk, Merck, Boehringer, Sanofi Aventis, and Bristol Myers Squibb; has received payment for manuscript preparation from the Canadian Society of Endocrinology and Metabolism (prior paper on incretins); has received payment for development of educational presentations including service on speakers' bureaus from Novo Nordisk (CME presentation for CDA 2012); has received Travel/accommodations expenses covered or reimbursed for travel to conferences or to teaching events from Merck, Novo Nordisk, Eli Lilly, Boehringer,
Sanofi, BMS; has performed research studies of new DM or obesity medications for Novo Nordisk, Eli Lilly, Boehringer, Johnson\&Johnson, Sanofi, BMS.

\section{References}

Papers of particular interest, published recently, have been highlighted as:

•• Of major importance

1. National Diabetes Statistics, 2011: Fast Facts on Diabetes. National Institute of Diabetes and Digestive and Kidney Diseases of the National Institutes of Health. http://diabetes.niddk.nih.gov/dm/pubs/ statistics/ Accessed online 8.Sep.2012.

2. Prevalence of Obesity in the United States, 2009-2010: NCHS Data Brief. http://www.cdc.gov/nchs/data/databriefs/db82.pdf January 2012. Accessed online 8.sept.2012.

3. Hu FB, Manson JE, Stampfer M, et al. Diet, lifestyle, and the risk of type 2 diabetes mellitus in women. $\mathrm{N}$ Engl J Med. 2001;345:790-7.

4. Eeg-Olofsson K, Cederholm J, Nilsson PM, et al. Risk of cardiovascular disease and mortality in overweight and obese patients with type 2 diabetes: an observational study in 13,087 patients. Diabetologia. 2009;52:65-73.

5. •- Meneghini LF, Orozco-Beltran D, Khunti K, et al. Weight beneficial treatments for type 2 diabetes. J Clin Endocrinol Metab. 2011;96(11):3337-53. This paper discusses treatments for T2DM treatment that have advantages from a weight management perspective.

6. Schmid C, Krayenbühl P, Wiesli P. Increased insulin dose requirement of long-acting insulin analogues in obese patients with type 2 diabetes. Diabetologia. 2009;52:2668-9.

7. Pani LN, Nathan DM, Grant RW. Clinical predictors of disease progression and medication initiation in untreated patients with type 2 diabetes and $\mathrm{A} 1 \mathrm{C}$ less than $7 \%$. Diabetes Care. 2008;31:386-90.

8. Hermansen K, Mortensen LS. Body weight changes associated with antihyperglycaemic agents in type 2 diabetes mellitus. Drug Saf. 2007;30:1127-42.

9. Phung OJ, Scholle JM, Talwar M, Coleman CI. Effect of noninsulin antidiabetic drugs added to metformin therapy on glycemic control, weight gain, and hypoglycemia in type 2 diabetes. JAMA. 2010;303(14):1410-8.

10. United Kingdom Prospective Diabetes Study (UKPDS) 13. Relative efficacy of randomy allocated diet, sulphonylurea, insulin, or metformin in patients with newly diagnosed non-insulin dependent diabetes followed for three years. BMJ. 1995;310:83-9.

11. Liu S-C, Chien M-N, Tu Y-K, Chien K-L. Effect of antidiabetic agents added to metformin on glycaemic control, hypoglycaemia and weight change in patients with type 2 diabetes: A network meta-analysis. Diabetes Obes Metab. 2012;14(9):810-20.

12. American Diabetes Association. Standards of medical care in diabetes-2010. Diabetes Care. 2010;33 Suppl 1:S11-61.

13. Rydén L, Standl E, Bartnik M, et al. Guidelines on diabetes, pre-diabetes, and cardiovascular diseases: executive summary. The Task Force on Diabetes and Cardiovascular Diseases of the European Society of Cardiology (ESC) and of the European Association for the Study of Diabetes (EASD). Eur Heart J. 2007;28:88-136.

14. Canadian Diabetes Association Clinical Practice Guidelines Expert Committee. Canadian Diabetes Association 2008 clinical practice guidelines for the prevention and management of diabetes in Canada. Can J Diabetes. 2008;32 suppl 1:S1-201. 
15. DeFronzo RA, Goodman AM. Efficacy of metformin in patients with non-insulin-dependent diabetes mellitus - The Multicenter Metformin Study Group. N Engl J Med. 1995;333:541-9.

16. Kahn SE, Haffner SM, Heis MA, et al. Glycemic durability of rosiglitazone, metformin, or glyburide monotherapy. N Engl J Med. 2006;355:2427-43.

17. Schernthaner G, Matthews DR, Charbonnel B, et al. Efficacy and safety of pioglitazone versus metformin in patients with type 2 diabetes mellitus: a double-blind, randomized trial. J Clin Endocrinol Metab. 2004;89(12):6068-76.

18. Dungan KM, Buse JB. Glucagon-like peptide 1-based therapies for type 2 diabetes: a focus on exenatide. Clin Diabetes. 2005;23:56-62.

19. Baggio LL, Drucker DJ. Biology of incretins: GLP-1 and GIP. Gastroenterology. 2007;132:2131-57.

20. Nauck MA, Kleine N, Orskov C, et al. Normalization of fasting hyperglycaemia by exogenous glucagon-like peptide 1 (7-36 amide) in type 2 (non-insulin-dependent) diabetic patients. Diabetologia. 1993:36:741-4.

21. Nauck MA, Niedereichholz U, Ettler R, et al. Glucagon-like peptide 1 inhibition of gastric emptying outweighs its insulinotropinc effects in healthy humans. Am J Physiol. 1997;273(5 Pt 1):E981-8.

22. Williams DL. Minireview: finding the sweet spot: peripheral versus central glucagon-like peptide 1 action in feeding and glucose homeostasis. Endocrinology. 2009;150:2997-3001.

23. Toft-Nielsen MB, Damholt MB, Madsbad S, et al. Determinants of the impaired secretion of glucagon-like peptide-1 in type 2 diabetic patients. J Clin Endocrinol Metab. 2001;86:3717-23.

24. Nauck M, Stöckmann F, Ebert R, Creutzfeldt W. Reduced incretin effect in type 2 (non-insulin dependent) diabetes. Diabetologia. 1986;29:46-52.

25. Vilsbøll T, Knop FK, Krarup T, et al. The pathophysiology of diabetes involves a defective amplification of the late-phase insulin response to glucose by glucose-dependent insulinotropic polypeptide-regardless of etiology and phenotype. J Clin Endocrinol Metab. 2003;88:4897-903.

26. Koliaki C, Doupis J. Incretin-based therapy: a powerful and promising weapon in the treatment of type 2 diabetes mellitus. Diabetes Ther. 2011;2(2):101-21.

27. Lind M. Incretin therapy and its effect on body weight in patients with diabetes. Prim Care Diabetes. 2012;6(3):187-91.

28. • Cornell S. Differentiating among incretin therapies: a multipletarget approach to type 2 diabetes. J Clin Pharm Ther. 2012. doi:10.1111/j.1365-2710.2012.01342.x. This paper compares and contrasts GLP-1 receptor agonists and DPP-4 inhibitors.

29. Aroda VR, Henry RR, Han J, et al. Efficacy of GLP-1 receptor agonists and DPP-4 inhibitors: meta-analysis and systematic review. Clin Ther. 2012;34(6):1247-58.

30. Scheen AJ, Charpentier G, Ostgren CJ, et al. Efficacy and safety of saxagliptin in combination with metformin compared with sitagliptin in combination with metformin in adult patients with type 2 diabetes mellitus. Diabetes Metab Res Rev. 2010;26:540-9.

31. Pi-Sunyer FX, Schweizer A, Mills D, et al. Efficacy and tolerability of vildagliptin monotherapy in drug-naïve patients with type 2 diabetes. Diabetes Res Clin Pract. 2007;76:132-8.

32. Garber AJ, Schweizer A, Baron MA, et al. Vildagliptin in combination with pioglitazone improves glycaemic control in patients with type 2 diabetes failing thiazolidinedione monotherapy: a randomized, placebo-controlled study. Diabetes Obes Metab. 2007;9:166-74.

33. Taskinen MR, Rosenstock J, Tamminen I, et al. Safety and efficacy of linagliptin as add-on therapy to metformin in patients with type 2 diabetes: a randomized, double-blind, placebocontrolled study. Diabetes Obes Metab. 2011;13:65-74.

34. Byetta тм product monograph. Eli Lilly Canada Inc., Toronto. Available at http://www.glucagon.com/pdfs/ByettaCanadaPM 11Jan2011_pswd.pdf Accessed September 2012.
35. Amori RE, Lau J, Pittas AG. Efficacy and safety of incretin therapy in type 2 diabetes: systematic review and meta-analysis. JAMA. 2007;298(2):194-206.

36. DeFronzo RA, Ratner RE, Han J, et al. Effects of exenatide (exendin-4) on glycemic control and weight over 30 weeks in metformin-treated patients with type 2 diabetes. Diabetes Care. 2005;28(5):1092-100.

37. Ratner RE, Magges D, Nielsen LL, et al. Long term effets of exenatide therapy over 82 weeks on glycaemic control and weight in overweight metformin-treated patients with type 2 diabetes mellitus. Diabetes Obes Metab. 2006;8(4):419-28.

38. Jelsing J, Vrang N, Hansen G, et al. Liraglutide: short-lived effect on gastric emptying- long lasting effects on body weight. Diabetes Obes Metab. 2012;14:531-8.

39. Niswender K, Pi-Sunyer X, Buse J, et al. Weight change with liraglutide and comparator therapies: an analysis of seven phase 3 trials from the liraglutide diabetes development programme. Diabetes Obes Metab. 2012. doi:10.1111/j.1463-1326.2012.01673.x.

40. Buse JB, Rosenstock J, Sesti G, et al. Liraglutide once a day versus exenatide twice a day for type 2 diabetes: a 26 -week randomised, parallel group, multinational, open-label trial (LEAD-6). Lancet. 2009;374:39-47.

41. Bydureon ${ }^{\circledR}$ prescribing information. Amylin Pharmaceuticals, Inc., San Diego. Available at www.documents.bydureon.com/ Bydureon_PI.pdf. Accessed September 2012.

42. Drucker $\bar{D} J$, Buse JB, Taylor K, et al. Exenatide once weekly versus twice daily for the treatment of type 2 diabetes: a randomized, open-label, non-inferiority study. Lancet. 2008;372:1240-50.

43. Buse JB, Nauck MA, Forst T, et al. Efficacy and safety of exenatide once weekly versus liraglutide in subjects with type 2 diabetes (DURATION-6): a randomized, open-label study. Diabetologia. 2011;54 Suppl 1:S38.

44. Barnett AH. Lixisenatide: evidence for its potential use in the treatment of type 2 daibetes. Core Evid. 2011;6:67-79.

45. Tzefos M, Harris K, Brackett A. Clinical efficacy and safety of once-weekly glucagon-like peptide-1 agonists in development for treatment of type 2 diabetes mellitus in adult. Ann Pharmacother. 2012;46(1):68-78.

46. Clinicaltrials.gov: A randomized controlled clinical triral in type 2 diabetes comparing semaglutide to placebo and liraglutide. Available at http://clinicaltrials.gov/ct2/show/NCT00696657?term= semaglutide\&rank=2 Accessed September 2012.

47. Davies M, Pratley R, Hammer M, et al. Liraglutide improves treatment satisfaction in people with Type 2 diabetes compared with sitagliptin, each as an add on to metformin. Diabet Med. 2011;28(3):333-7.

48. Poster M, Zanutto E, McDonald S, et al. A comparison of preferences for two GLP-1 products - liraglutide and exenatide - for the treatment of type 2 diabetes. J Med Econ. 2010;13(4):655-61.

49. Davies M, Speight J. Patient-reported outcomes in trials of incretin-based therapies in patients with type 2 diabetes mellitus. Diabetes Obes Metab. 2012;14(10):882-92.

50. Buse J, Bergenstal RM, Glass LC, et al. Add-on of twice-daily exenatide to basal insulin-treated patients with type 2 diabetes: a randomized, controlled Trial. Ann Intern Med. 2011;154:103-12.

51. DeVries JH, Bain SC, Rodbard HW, et al. Sequential intensification of metformin treatment in type 2 diabetes with liraglutide followed by randomized addition of basal insulin prompted by A1C targets. Diabetes Care. 2012;35(7):1446-54.

52. Bain SC, DeVries JH, Seufert J, et al. Adding insulin detemir (IDet) to liraglutide and metformin improves glycaemic control with sustained weight reduction and low hypoglycaemia rate: 52 week results. Diabetologia. 2011;54 Suppl 1:S37.

53. Astrup A, Rossner S, Van Gaal L, et al. Effects of liraglutide in the treatment of obesity: a randomised, double-blind, placebocontrolled study. Lancet. 2009;374(9701):1606-16. 
54. Astrup A, Carraro R, Finer N, et al. Safety, tolerability and sustained weight loss over 2 years with the once-daily human GLP-1 analog, liraglutide. Int J Obes. 2012;36(6):843-54.

55. Rosenstock J, Klaff LJ, Schwartz S, et al. Effects of exenatide and lifestyle modification on body weight and glucose tolerance in obese subjects with and without pre-diabetes. Diabetes Care. 2010;33(6):1173-5.

56. Dushay J, Gao C, Gopalakrishnan GS, et al. Short-term exenatide treatment leads to significant weight loss in a subset of obese women without diabetes. Diabetes Care. 2012;35(1):4-11.

57. Sabino-Silva R, Mori RC, David-Silva A, et al. The $\mathrm{Na}(+) /$ glucose cotransporters: from genes to therapy. Braz J Med Biol Res. 2010;43(11):1019-26.

58. Patel AK, Fonseca V. Turning glucosuria into a therapy: efficacy and safety with SGLT2 inhibitors. Curr Diab Rep. 2010;10 (2):101-7

59. • Ghosh RK, Ghosh SM, Chawla S, Jasdanwala SA. SGLT2 inhibitors: a new emerging therapeutic class in the treatment of type 2 diabetes mellitus. J Clin Pharmacol. 2012;52(4):457-63. This is a thorough review of SGLT2 physiology and clinical development of SGLT2 agents.

60. European Medicines Agency. Summary of opinion (initial authorization) - dapagliflozin. EMA/CHMP/259852/2012. 19 April 2012. Available at http://www.ema.europa.eu/docs/en_GB/document library/Summary of opinion - Initial authorisation/human/ 002322/WC500125684.pdf. Accessed September 2012.

61. Bailey CJ, Gross JL, Pieters A, Bastien A, List JF. Effect of dapagliflozin in patients with type 2 diabetes who have inadequate glycaemic control with metformin: a randomised, double-blind, placebo-controlled trial. Lancet. 2010;375:2223-33.

62. Nauck MA, Del Prato S, Meier JJ, et al. Dapagliflozin versus glipizide as add-on therapy in patients with type 2 diabetes who have inadequate glycemic control with metformin: a randomized, 52-week, double-blind, active-controlled noninferiority trial. Diabetes Care. 2011;34(9):2015-22.

63. Bolinder J, Ljunggren Ö, Kullberg J, et al. Effects of dapagliflozin on body weight, total fat mass, and regional adipose tissue distribution in patients with type 2 diabetes mellitus with inadequate glycemic control on metformin. J Clin Endocrinol Metab. 2012;97 (3):1020-31.

64. Wilding JP, Woo V, Soler NG, et al. Long-term efficacly of dapagliflozin in patients with type 2 diabetes mellitus receiving high doses of insulin: a randomized trial. Ann Intern Med. 2012;156(6):405-15.

65. FDA Briefing Document. NDA 202293. Dapagliflozin Tablets, 5 and $10 \mathrm{mg}$. Sponsor: Bristol-Myers Squibb. Advisory Committee Meeting. 2011. Jul 19. Available at http://www.fda.gov/
downloads/Advisory Committees/CommitteesMeetingMaterials/ Drugs/Endocrinologic and Metabolic DrugsAdvisory Committee/ UCM262994.pdf. Accessed September 2012.

66. Rosenstock J, Aggarwal N, Polidori D, et al. Dose-ranging effects of canagliflozin, a sodium-glucose cotransporter 2 inhibitor, as add-on to metformin in subjects with type 2 diabetes. Diabetes Care. 2012;35(6):1232-8.

67. Younk LM, Mikeladze M, Davis SN. Pramlintide and the treatment of diabetes: a review of the data since its introduction. Expert Opin Pharmacother. 2011;12(9):1439-51.

68. Roth JD, Maier H, Chen S, Roland BL. Implications of amylin receptor agonism: integrated neurohormonal mechanisms and therapeutic applications. Arch Neurol. 2009;66(3):306-10.

69. Hollander P, Maggs DG, Ruggles JA, et al. Effect of pramlintide on weight in overweight and obese insulin-treated type 2 diabetes patients. Obes Res. 2004;12(4):661.

70. Riddle M, Frias J, Zhang B, et al. Pramlintide improved glycemic control and reduced weight in patients with type 2 diabetes using basal insulin. Diabetes Care. 2007;11:2794-9.

71. Riddle M, Pencek R, Charenkavanich S, et al. Randomized comparison of pramlintide or mealtime insulin added to basal insulin treatment for patients with type 2 diabetes. Diabetes Care. 2009;32 (9):1577-82.

72. Symlin(R) [package insert]. San Diego, CA: Amylin Pharmaceuticals; 2008. Available at https://www.symlin.com/pdf/symlin-picombined.pdf Accessed September 2012.

73. Amylin and Takeda discontinue development of pramlintide/ metreleptin combination treatment for obesity following commercial reassessment of the program. Available at http://www.takeda. $\mathrm{com} /$ press/article_42791.html. Accessed September 2012.

74. Rosenstock J, Fonseca VA, Garvey WT, et al. Initial combination therapy with metformin and colesevelam for achievement of glycemic and lipid goals in early type 2 diabetes. Endocr Pract. 2010;16(4):629-40.

75. Bays HE. Colesevelam hydrochloride added to background metformin therapy in patients with type 2 diabetes mellitus: a pooled analysis from 3 clinical studies. Endocr Pract. 2011;17(6):933-8.

76. Ganda OP. The role of bile acid sequestrants in the management of type 2 diabetes mellitus. Metab Syndr Relat Disord. 2010;8 Suppl $1:$ S15-21.

77. Welchol (Colesevelam) prescribing information. Daiichi Sankyo, Inc., Parsippany, New Jersey. Available at http://www.accessdata. fda.gov/drugsatfda_docs/label/2008/021176s017lbl.pdf. Accessed September 2012.

78. Younk LM, Davis SN. Evaluation of colesevelam hydrochloride for the treatment of type 2 diabetes. Expert Opin Drug Metab Toxicol. 2012;8(4):515-25. 